\title{
Monoclonal T-cell Receptor Anti-CD3 scFv Fusion Protein IMCgp100
}

National Cancer Institute

\section{Source}

National Cancer Institute. Monoclonal T-cell Receptor Anti-CD3 scFv Fusion Protein

IMCgp100. NCI Thesaurus. Code C94208.

A fusion protein containing a modified form of human T-cell receptor (TCR) specific for the gp100 antigen and fused to an anti-CD3 single-chain antibody fragment, with potential antineoplastic activity. Upon direct intratumoral administration of IMCgp100 into the melanoma lesion, the TCR moiety of this agent targets and binds to the tumor associated antigen (TAA) gp100 presented on the melanoma tumor cell; the anti-CD3 fragment moiety binds to CD3- expressing T lymphocytes, thereby selectively crosslinking tumor cells and T-lymphocytes. This may lead to the recruitment of cytotoxic T lymphocytes (CT L) to the T lymphocyte/tumor cell aggregates and result in CT Lmediated death of gp100-expressing melanoma cancer cells. 